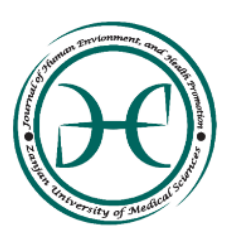

Journal of Human, Environment and Health Promotion

Journal homepage: www.zums.ac.ir/jhehp

\title{
The Photocatalytic Kinetics of the Methyl Orange Degradation in the Aqueous Suspension of Irradiated $\mathrm{TiO}_{2}$
}

\author{
Nahid Nabavi a , Mazyar Peyda ${ }^{a, *}$, Gholamreza Sadeghi ${ }^{\text {a }}$ \\ ${ }^{a}$ Department of Environmental Health Engineering, School of Public Health, Zanjan University of Medical \\ Sciences, Zanjan, Iran.
}

*Corresponding author. E-mail address: mazyarpeyda @ yahoo.com

\section{A R T I C L E I N F O}

Article history:

Received April 24, 2017

Accepted May 31, 2017

Article Type:

Original Article

Keywords:

Methyl Orange

Photocatalytic

AOP

Kinetics

\begin{abstract}
A B S T RA C T
Background: In the present study, the photocatalytic $\left(\mathrm{TiO}_{2} / \mathrm{UV}\right)$ batch process has been used for the methyl orange (MO) degradation.

Methods: In the catalyst range from 0.25 to $1.5 \mathrm{~g} / \mathrm{L}$, the optimum concentration of $\mathrm{TiO}_{2}$ was found to be $0.5 \mathrm{~g} / \mathrm{L}$. The kinetic behavior of MO degradation has been evaluated using the non-linear form of pseudo-first order and pseudo-second order models.

Results: The goodness of the fit was evaluated using the correlation coefficient R2 value and the mean square error (MSE) function.

Conclusion: The kinetic studies revealed that the pseudo-first order model $\left(\mathrm{k}_{1}=-0.0593\right.$

$\left.\mathrm{min}^{-1}\right)$ is more suitable to fit the experimental data $\left(\mathrm{R}_{2}=0.957, \mathrm{MSE}=0.00271\right)$ of $\mathrm{MO}$ degradation.
\end{abstract}

\section{Introduction}

The advanced oxidation processes (AOPs) has been used as an alternative for the mineralization of recalcitrant molecules as well as microorganisms. Due to low cost, environmentally friendly nature, and low residuals of $\mathrm{TiO}_{2} / \mathrm{UV}$ it has drawn more attentions in water and wastewater treatment studies [1].

The AOP has demonstrated its efficiency in degrading a wide range of ambiguous refractory organics and pathogens [1]. These advanced oxidation processes can be classified as homogeneous or as heterogeneous. Homogeneous:
The photocatalysis refers to those photocatalytic processes where the reactants and the photocatalyst exist in the same phase during the reaction. The term heterogeneous refers to the fact that the contaminants are present in the aqueous phase, while the catalyst is in the solid phase [2].

The usual applications of some features of heterogeneous photocatalysis have been extended such as: 1) ambient operating pressure and temperature, 2) full mineralization of parents and intermediary compounds with no secondary contamination, and 3) small operating costs [1].

To cite: Nabavi N, Peyda M, Sadeghi Ghr. The Photocatalytic Kinetics of the Methyl Orange Degradation in the Aqueous Suspension of Irradiated $\mathrm{TiO}_{2}$. J Hum Environ Health Promot. 2017; 2(3):154-160. 
Among the semiconductor catalysts, Titanium dioxide $\left(\mathrm{TiO}_{2}\right)$, which is one of the most basic materials in our daily life, has received the greatest interest in research for the environmental purification [3].

$\mathrm{TiO}_{2} / \mathrm{UV}$ has become a photocatalytic decontamination process for a large variety of organics. Organics can be totally degraded and mineralized to $\mathrm{CO}_{2}, \mathrm{H}_{2} \mathrm{O}$, and harmless inorganic anions. This performance is attributed to hydroxyl radicals (HO•) that are known as indiscriminate oxidizing agents. The oxidizing potential of this radical is $2.80 \mathrm{~V}$ which is being exceeded only by fluorine [4].

The light of wavelength about $365 \mathrm{~nm}$ (median pressure lamps) is appropriate for the photocatalysis with titanium dioxide that has a threshold energy equal to $413 \mathrm{~nm}$, therefore activation needs smaller wavelengths than these ones. The median pressure lamps give the most energy output that is more than $300 \mathrm{~nm}$, reaching to its highest climax at $365 \mathrm{~nm}$, and slumping above about $600 \mathrm{~nm}$. It has been proven that irradiation with $254 \mathrm{~nm}$ light can operate synergic ally with $365 \mathrm{~nm}$ light to enhance the photo catalytic kinetics several-fold [5].

It was shown that phenol degradation using anatase $\mathrm{TiO}_{2}$ as a photocatalyst can be predicted using the first-order kinetics [6]. In a photo catalytic study, dyes are one of the most common model compounds that were used not only to represent a persistent water pollutant, but also when they dissolved in water the bleaching of the dye during the reaction provides a quick and simple qualitative response [7].

A number of investigations have been reported on the photo catalytic degradation of the methyl orange (MO). The degradation of MO was found to be dependent on the initial concentration of nano catalyst, $\mathrm{pH}$ and contact time. The methyl orange is clearly visible, even at concentrations as low as $1 \mathrm{ppm}$, and it can be readily quantified using the UV-Vi spectroscopy. Due to both its stable nature and easy quantification, the methyl orange is frequently used as a model pollutant for the comparative studies of photocatalytic systems [8]. The methyl Orange is an azo dye with the molecular formula of $\mathrm{C}_{14} \mathrm{H}_{14} \mathrm{~N}_{3} \mathrm{NaO}_{3} \mathrm{~S}$ and its molecular mass is 327.34 ( $\mathrm{g} / \mathrm{mol})$ [9].

The methyl orange is an organic dye used as a $\mathrm{pH}$ indicator in the titration. Many studies revealed the toxicity and carcinogenic nature of this dye. If this colorant is associated with certain drugs in the human body it can induce the allergic and asthmatic reactions in sensitive people. An additional difficulty is that, when it's present, this dye cannot be removed normally by the conventional waste water treatment systems.

Therefore, the effluents must be treated before being released into water bodies [10].

The ionic state of MO makes this compound essentially non-volatile, therefore MO should exist solely in the particulate phase in the ambient atmosphere. Based on the limited data, this compound is expected to be resistant to aerobic biodegradation in both soil and water; the MO was not degraded over 5 days in an aqueous BOD screening test. Due to its ionic nature the loss of the dye from water surfaces by volatilization should not be important. The potential for $t$ bio concentration in the aquatic organisms is expected to be low based on an estimated bio concentration factor $(\mathrm{BCF})$ of 30 [11].

Therefore this research intends to show the methyl orange degradation and the kinetics by the photocatalytic process.

\section{Materials and Methods}

$\mathrm{TiO}_{2}$ nanoparticles (Plasma Chem, $21 \mathrm{~nm}$ particle size, $99.5 \%$ and $15 \ldots 50 \mathrm{~m}^{2} / \mathrm{g}$ surface area) was used as a photocatalyst [9]. A UV lamp (6 W UV-C) was used as the UV-light source. Experiments were carried out in a $500 \mathrm{~mL}$ photo reactor. All experiments were performed at $\mathrm{pH} 7$.

The MO was purchased from Merck (Germany).

\subsection{The Operational parameters}

It has been demonstrated that the catalyst dosage, character and the initial concentration of 
the target compound, the coexisting compound, the UV light intensity, the oxygen concentration, the presence of supplementary oxidizable substance, the temperature, the circulating flow rate, the $\mathrm{pH}$ for aqueous treatments, and the water concentration for gaseous phases photoreactions are the main parameters affecting the degradation rate [4].

The methyl Orange Was used as the model pollutants. The MO degradation experiment by $\mathrm{TiO}_{2} / \mathrm{UV}$ system was performed in the batch photocatalytic reactor containing 2 sets of lamps (6 W) and the magnetic Stirrer. The MO was dissolved in the distilled water. The change in concentration of MO during time intervals was recorded with respect to parameters such as the catalyst value and the reaction time. In order to evaluate the optimum concentration of $\mathrm{TiO}_{2}$ nanoparticles, the catalyst in the range of $0.25-$ $1.5 \mathrm{~g} / \mathrm{l}$ was used. A volume of $200 \mathrm{ml}$ of $\mathrm{MO}$ solution with a $19.77 \mathrm{mg} / \mathrm{l}$ initial dye concentration was agitated with a known value of catalyst. The samples were taken after a 20 minute reaction. The experiments were carried out in triplicate. Then they were centrifuged by a centrifuge (CE-148) at $4000 \mathrm{rpm}$ for 20 minutes. In order to remove the catalyst particles completely; the amount of dye was measured by spectrophotometer $\left(\mathrm{HACH} \mathrm{D}_{\mathrm{r}}, 5000\right)$ at $\lambda_{\max }=465$ $\mathrm{nm}$.

The percentage of degradation was calculated using the equation given below:

$$
\operatorname{Degradation}(\%)=\frac{C_{0}-C_{E}}{C_{0}} \times 100
$$

After selecting the optimum catalyst concentration, the optimum reaction time was investigated. The optimum weight of catalyst for maximum degradation was added to $200 \mathrm{ml} \mathrm{MO}$ solution in a reactor and the contents were shaken at the room temperature. The samples were withdrawn at 5 minute intervals. The efficiency of optimum concentration was calculated via the above equation.

\subsection{The kinetic studies}

In the present study, the experimental kinetic data for $\mathrm{MO}$ degradation using $\mathrm{TiO}_{2} / \mathrm{UV}$ were fitted to the Lagergren`s pseudo first-order and Ho`s pseudo second-order model. The summary of the kinetic model expressions were given in Table 1 .

Table 1: The summary of Kinetic Models Used in the Present Study.

\begin{tabular}{|c|c|c|}
\hline Kinetic models & Parameters & Reference \\
\hline $\begin{array}{c}\text { Pseudo first-order } \\
q_{t}=q_{t}\left(1-e^{-K_{1} t}\right)\end{array}$ & $\begin{array}{l}\mathrm{K}_{1} \text { : The pseudo first- } \\
\text { order rate constant } \\
\quad\left(\mathrm{min}^{-1}\right) \\
\mathrm{q}_{\mathrm{e}} \text { : Degradation at } \\
\text { equilibrium }\left(\mathrm{g} \mathrm{g}^{-1}\right) \\
\mathrm{q}_{\mathrm{t}} \text { : Degradation at } \\
\text { time } \mathrm{t}\left(\mathrm{g} \mathrm{g}^{-1}\right)\end{array}$ & [12] \\
\hline $\begin{array}{l}\text { Pseudo second- order } \\
q_{t}=\frac{K_{2} q_{e}{ }^{2} t}{1+K_{2} q_{e} t}\end{array}$ & $\begin{array}{l}\mathrm{K}_{2} \text { : The pseudo- } \\
\text { second order rate } \\
\text { constant }\left[\mathrm{g}\left(\mathrm{g} \mathrm{min}^{-1}\right.\right. \\
\text {, } \\
\text { qe: Degradation at } \\
\text { equilibrium }\left(\mathrm{g} \mathrm{g}^{-1}\right) \\
\mathrm{q}_{\mathrm{t}}: \text { Degradation at } \\
\text { time } \mathrm{t}\left(\mathrm{g} \mathrm{g}^{-1}\right)\end{array}$ & [13] \\
\hline
\end{tabular}

The goodness of fit between the model and the experimental kinetic data was assessed using the presented error functions in Table 2. The determination coefficient was also applied to confirm the agreement between the experimental data and kinetic equations.

It has been shown that the non-linear method is more appropriate than the linear method for fitting the kinetic models [15]. Therefore, a trial and error nonlinear procedure was used to determine the kinetic parameters by minimizing the MSE between the experimental data and the predicted values using the Solver Add-on with Microsoft Microsoft Excel Spreadsheet.

\section{Results and Discussion}


The determination of optimum $\mathrm{TiO}_{2}$ nanoparticle concentration is one of the most important, fundamental and economical parameters in the degradation of dyes. In order to avoid the use of extra catalyst, determining the optimum concentration of catalyst is essential to maximize the dye removal efficiency [16].

(Fig. 1) shows that, the maximum MO degradation (initial concentration of $19.77 \mathrm{mg} / \mathrm{l}$ ) reached at $\mathrm{TiO}_{2}$ equal to $0.5 \mathrm{~g} / \mathrm{l}$.
It has been observed that the maximum decolonization efficiency in this optimum concentration was $81.08 \%$ and decreased as nanoparticle concentrations increases. The possible reason for this behavior may be raising the turbidity value of the solution and consequently, increasing the opacity and light scattering and decreasing the degradation efficiency [17].

Table 2: The explanation of error functions in the statistical analysis.

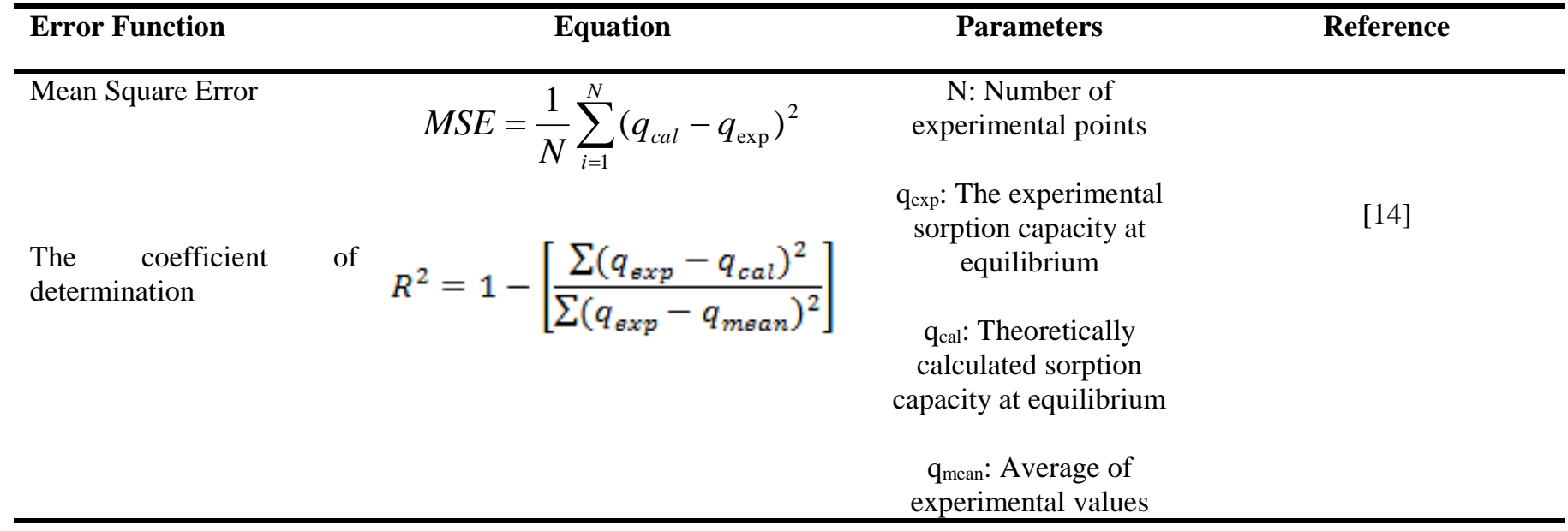

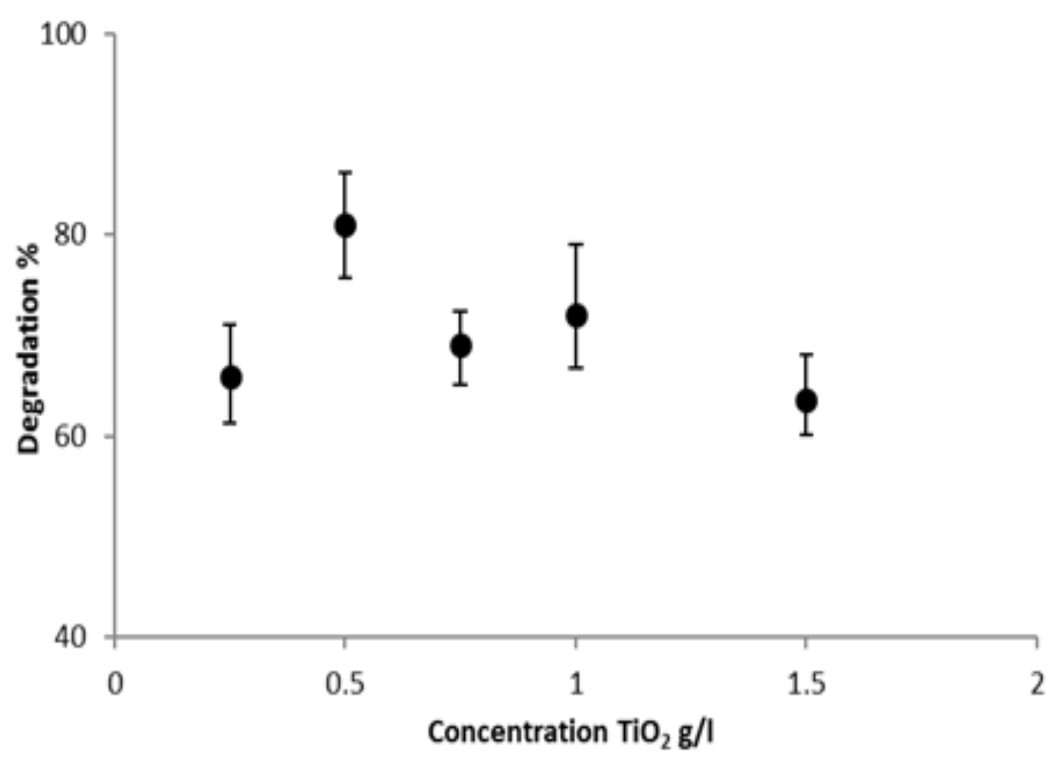

Fig. 1: The Effect of $\mathrm{TiO}_{2}$ concentration (0.25- $\left.1.5 \mathrm{~g} / \mathrm{l}\right)$ on the Methyl Orange degradation $(19.77 \mathrm{mg} / \mathrm{l})$. 


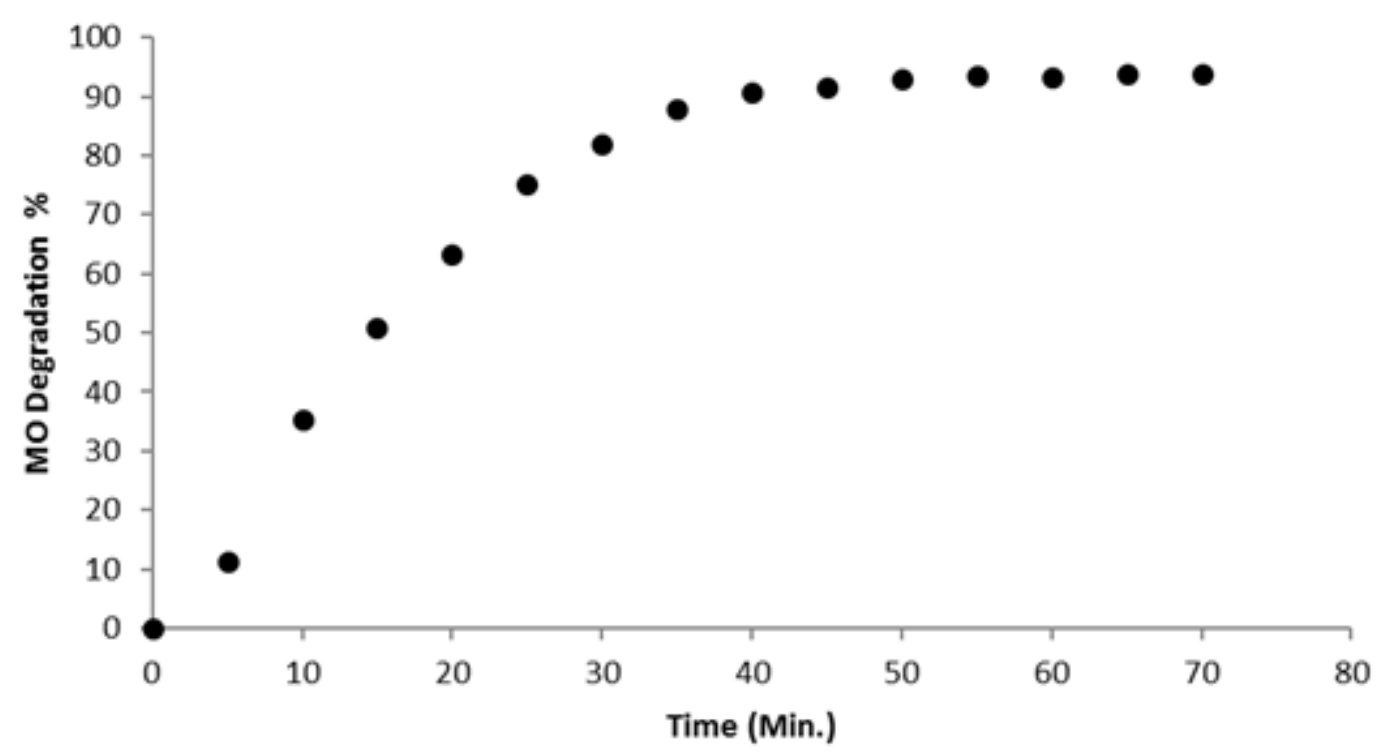

Fig. 2: The Effect of photocatalytic reaction time on Degradation efficiency of Methyl Orange (MO).

The Degradation of methyl orange during the reaction time of 5 to 70 minutes of photocatalytic reaction at 5-minute intervals was investigated.

The findings of this study demonstrate that after 55 minutes of reaction, the degradation reaches its plateau (93\%). These results may be explained by large number of binding sites available in the $\mathrm{TiO}_{2}$ nanoparticle at the initial period of reaction, the decolonization process accomplished slowly due to the saturation of binding sites and consequently was repulsive between the adsorbed molecules on the surface of nanoparticle and MO molecules in solution.

The predicted degradation profile of MO kinetic models is displayed in Fig. 3. The experimental data are also shown for the visual comparison of the fitting. The correlation coefficient $\left(\mathrm{R}_{2}\right)$ and (MSE) demonstrated that the pseudo-first order kinetic model fitted the MO degradation experimental data better than the two others.

The calculated kinetic parameters of the studied models as well as predicted $\mathrm{q}_{\mathrm{e}}$ values by nonlinear analysis are given in Table 3.

From Table 3, it is evident that the first order model is adequate to explain the degradation of
MO with higher values of the coefficient of determination appropriately $\left(\mathrm{R}_{2}\right)$ which is equal to 0.957 and the lower values of MSE are equal to 0.00271 compared to the second order model.

\section{Conclusion}

This study confirms that the degradation efficiency of MO is reduced by increasing the amount of nanoparticles. It is proposed that increasing the turbidity of solution as well as light scattering is responsible for this phenomenon. The Photocatalytic degradation of the Methyl-orange is best suited to the quasi-first-order kinetics model. 


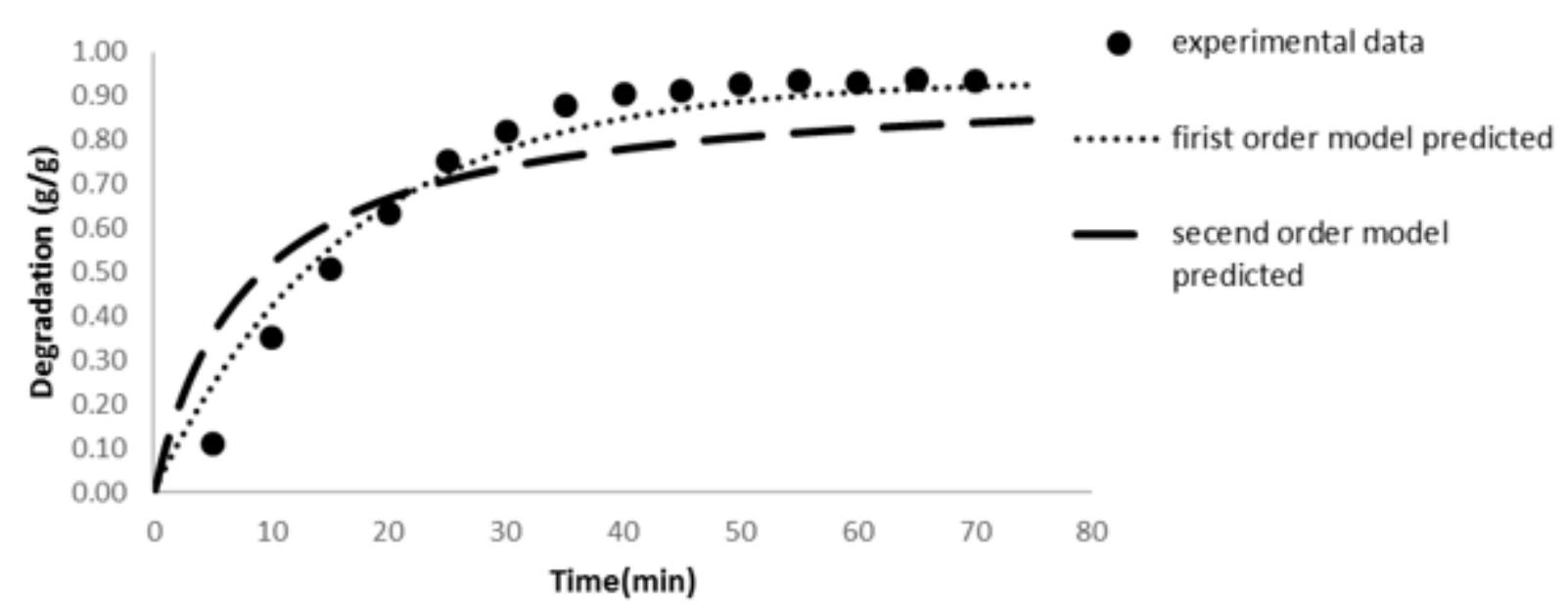

Fig. 3: The non-Linear plots for the pseudo-first and second order kinetic model for the methyl orange degradation.

Table 3: The Kinetic parameters obtained by fitting the experimental data to the pseudo-first and pseudo-second order model for the methyl orange photocatalytic degradation.

\begin{tabular}{|c|c|c|}
\hline Kinetic model & Parameters & Methyl orange Degradation \\
\hline \multirow[t]{4}{*}{ Pseudo first- order } & $\mathrm{q}_{\mathrm{e}}\left(\mathrm{g} \mathrm{g}^{-1}\right)$ & 0.937 \\
\hline & $\mathrm{K}_{1}\left(\min ^{-1}\right)$ & -0.0593 \\
\hline & $\mathrm{R}_{2}$ & 0.957 \\
\hline & MSE & 0.00271 \\
\hline \multirow[t]{4}{*}{ Pseudo second-order } & $\mathrm{q}_{\mathrm{e}}\left(\mathrm{g} \mathrm{g}^{-1}\right)$ & 0.937 \\
\hline & $\mathrm{K}_{2}\left[\mathrm{~g}(\mathrm{~g} \mathrm{~min})^{-1}\right]$ & 0.132920888 \\
\hline & $\mathrm{R}_{2}$ & 0.758075817 \\
\hline & MSE & 0.01519 \\
\hline
\end{tabular}

\section{References}

1. Chong MN, Jin B, Chow CW, Saint C. Recent Developments in Photocatalytic Water Treatment Technology: A Review. Water Res. 2010; 44(10): 2997-30.

2. John EM, Shaike JM. Chlorpyrifos: Pollution and Remediation. Environ Chem Lett. 2015; 13(3): 269-91.

3. Fujishima A, Rao TN, Tryk DA. Titanium Dioxide Photocatalysis. J Photochem Photobiol C: Photochem Reviews. 2000; 1(1):1-21.
4. Carp O, Huisman CL, Reller A. Photoinduced Reactivity of Titanium Dioxide. Prog Solid State Chem. 2004; 32(1): 33-177.

5. Bickley R, Slater M, Wang W-J. Engineering Development of a Photocatalytic Reactor for Waste Water Treatment. Process Saf Environ Prot. 2005; 83(3): 205-16.

6. Okamoto K-I, Yamamoto Y, Tanaka H, Itaya A. Kinetics of Heterogeneous Photocatalytic Decomposition of Phenol Over Anatase $\mathrm{TiO}_{2}$ 
Powder. Bull Chem Sci Japan. 1985; 58(7): 20238.

7. Gilmour CR. Water Treatment Using Advanced Oxidation Processes: Application Perspectives. 2012.

8. Pettit SL. Investigation of $\mathrm{TiO}_{2}$ and $\mathrm{InVO}_{4}-\mathrm{TiO}_{2}$ Semiconductors for the Photocatalytic Degradation of Aqueous Organics. 2014.

9. Mehra M, Sharma T. Photo Catalytic Degradation of Two Commercial Dyes in Aqueous Phase Using Photo Catalyst $\mathrm{TiO}_{2} . A d v$ Appl Sci Res. 2012; 3(2): 849-53.

10. Mukherjee D. Development of a Novel $\mathrm{TiO}_{2-}$ Polymeric Film Photocatalyst for Water Purification Both Under UV and Solar Illuminations: Ph. D. Thesis. 2011.

11. HSDB. National library of Medicine. Bethseda, Maryland. Available from: URL: http://toxnet nlm nih gov/cgi-bin/sis/search2/f.

12. Lagergren, S. About the Theory of So-Called Adsorption of Soluble Substances. K Svenska Vetenskapsakademiens Handl. 1898; 24(4): 1-39.

13. Howard P, Meylan W, Aronson D, Stiteler W, Tunkel J, Comber M, Parkerton TF. A New Biodegradation Prediction Model Specific to Petroleum Hydrocarbons. Environ Toxicol Chem. 2005; 24(8): 1847-13.

14. Ncibi MC. Applicability of Some Statistical Tools to Predict Optimum Adsorption Isotherm after linear and Non-linear Regression Analysis. $J$ Hazard Mater. 2008; 153 (1-2): 207-212.

15. Kumar KV. Linear and Non-linear Regression Analysis for the Sorption Kinetics of Methylene Blue onto Activated Carbon. J Hazard Mater. 137(3): 1538-1544.

16. Rahimi S, Ehrampoush MH, Ghaneian MT, Reshadat S, Fatehizadeh A, Ahmadian M, et al. Application of $\mathrm{TiO}_{2} / \mathrm{UV}-\mathrm{C}$ Photocatalytic Process in Removal of Reactive Red 198 dye from
Synthetic Textile Wastewater. Asian J Chem. 2013; 25(13): 7427.

17. Sohrabi M, Ghavami M. Photocatalytic Degradation of Direct Red 23 dye Using UV/TiO 2: Effect of Operational Parameters. J Hazard Mater. 2008; 153(3): 1235-9. 